\title{
Planting Time and Pesticide Application on the Agronomic Performance of Chickpea in Semi-arid Zone, South Western Uganda
}

\author{
Peace Kankwatsa ${ }^{1}$, Robert Muzira ${ }^{1, *}$, Steven Byenkya ${ }^{2}$ \\ ${ }^{1}$ National Agricultural Research Organization, Mbarara Zonal Agricultural Research and Development Institute \\ (MBAZARDI), P.O. Box 389, Mbarara, Uganda \\ ${ }^{2}$ National Agricultural Research Organization, Bulinda Zonal Agricultural Research and Development Institute (BUZARDI), \\ P.O. Box 101, Hoima, Uganda \\ *Corresponding author: nrmuzira@gmail.com
}

\begin{abstract}
Chickpea (Cicer arietinum L.) is an under-utilised food legume in Uganda with great potential to contribute to household food, nutrition and income security. The objective of this study was to investigate the effects of planting time on the agronomic performance of Desi and Kabuli chickpea genotypes. The study was conducted on-station in Mbarara district during the 2011A,B and 2012A seasons. In the 2011A season, the unusual shorter rainfall and high temperatures favoured high pod borer (Helicoverpa armigera) infestation that resulted in low grain yields (347-521 kg ha-1). In the excessively rainy and cool long 2011B season, chickpea planted before and at the onset of rainfall had high Ascochyta blight plant infection. The highly wet and dry conditions significantly $(\mathrm{P} \leq 0.05)$ reduced the grain yields $\left(400 \mathrm{t} \mathrm{ha}^{-1}\right)$ of chickpea, to below its potential of 1000-3000 kg ha ${ }^{-1}$. Crops that coincided with well distributed rains alternating with sufficient sunshine (planted in late March 2012A) had higher yields $\left(>1200 \mathrm{~kg} \mathrm{ha}^{-1}\right)$. Yield losses associated with pests and diseases were managed when sowing was done after the peak of the rain season (end of March and October). Therefore, chickpea requires moderately low well distributed rains, with adequate sunny days during the vegetative and reproduction stages for higher grain yields. Integration proper planting time, variety and judicial pesticide application constituted the appropriate strategy for pod borer and Ascochyta blight management for the enhanced chickpea agronomic performance in the South Western Agro Ecological Zone of Uganda.
\end{abstract}

Keywords: chickpea, agronomic performance, Ascochyta blight, Helicoverpa armigera, SWAEZ Uganda

Cite This Article: Kankwatsa P., Muzira R., and Byenkya S. "Planting Time and Pesticide Application on the Agronomic Performance of Chickpea in Semi-arid Zone, South Western Uganda." World Journal of Agricultural Research, vol. 6, no. 2 (2018): 49-57. doi: 10.12691/wjar-6-2-3.

\section{Introduction}

Chickpea (Cicer arietinum L.) is a cool season food legume, grown as a winter crop in the tropics and as a summer or spring crop in temperate environments. Although chickpea tolerates heat, drought [1] and low soil fertility conditions $[2,3]$, it is very sensitive to very high daily temperature $>35^{\circ} \mathrm{C}$ and very low daily temperature $<15^{\circ} \mathrm{C}$, especially during the reproductive stages [4]. Both extreme temperatures lead to flower abortion, low flowering and pod setting. Chickpea is usually grown in the post rain season or fallow in major production regions, but late sown crops often experience moisture stress and high temperatures at critical stage of pod-filling, leading to yield and seed/grain quality reduction $[4,5]$.

Chickpea was first evaluated on sandy loam soils for its agronomic performance in the South-Western Agro-Ecological Zone (SWAEZ) of Uganda in 1993. The results indicated that chickpea had a high potential to be grown in the zone as an additional crop to banana (ICRISAT, 2007). While in other regions famous for chickpea production, the crop is grown on black cotton soils, the soils in the SWAEZ are typically sandy loam, with low water holding capacity [6,7]. The study carried out in Ntungamo and Mbarara districts showed that chickpea is best planted earlier in the rain season on the dominant sandy loam clay soils. Although early planting ensures availability of sufficient moisture in the existing soils to support chickpea growth, on the contrary, such conditions also favour severe epidemics of Ascochyta blight [caused by Ascochyta rabiei (Pass.) Labrousse], the major chickpea production constraint [8,9].

Given the semi-arid climatic and poor soil conditions of the SWAEZ, there was need to determine the most appropriate planting time for chickpea production. Elsewhere, studies have shown that late planted chickpea experiences high insect pest infestation, of which the pod borer (Helicoverpa armigera) is the most destructive during the dry seasons [10], causing high grain losses in major chickpea producing regions [11]. Although this pest is usually controlled with insecticides, majority of the small-holder farmers can not afford insecticide applications at recommended rates. 
Globally, Ascochyta blight is the most important chickpea fungal disease [12], which severely affects chickpea growth and grain yields during the high rainfall periods. High rainfall intensity, coupled with high plant vegetative cover, create cool and humid micro-climates that favours rapid disease infection and spread. Its high epidemics occur under high humid conditions [13], which are experienced towards the peak of the cool-wet season in South Western Uganda. Under severe infection, 70-100\% grain yield losses due to Ascochyta blight have been reported $[8,9,14,15]$. The continuous evolution of highly virulent and aggressive pathotypes has constrained breeders' efforts to develop varieties with durable resistance $[12,16]$ partly because of the high level of pathotype viability resulting from sexual recombination.

The pod borer and Ascochyta blight attack on chickpea could be avoided if the crop is planted just after the peak rains. Integrating various practices including biological, cultural, varietal resistance and judicial pesticide application has been suggested to be a better strategy to enhance chickpea productivity, especially in areas where the pod borer pest [11,17] and Ascochyta blight are serious problems. The most appropriate planting period for the high agronomic performance of chickpea in the semi-arid area of Uganda and Sub-Saharan Africa in general has not been well studied. It was envisaged that obtaining the appropriate period for planting chickpea would result into increased grain yields with low investment in pest and disease management. Therefore, in order to ensure and sustain higher chickpea production in the zone, the appropriate planting periods that are unfavourable to the major pests and diseases but favourable to crop growth needs to be investigated. Hence, a study was carried out in the semiarid zone of South-western Uganda to assess the effects of planting time and pesticide application on agronomic performance of Desi and Kabuli genotypes of chickpea.

\section{Materials and Methods}

This study was conducted at Mbarara Zonal Agricultural Research and Development Institute (MBAZARDI) in South Western Uganda (SWAEZ). The SWAEZ has two annual rain seasons in March-June and August-December, with April and December being the peak rainfall months. The August-December rain season is considered long, and supports most crops. The dry spells occur in January-February and June-August. The field experiment was planted using high quality seeds of two chickpea genotypes; the Desi (ICCV 00108) and Kabuli (ICCV 92318) types, acquired from the International Crops Research Institute for the Semi-Arid Tropics (ICRISAT).

Plots of $3.0 \mathrm{~m} \times 3.6 \mathrm{~m}$ arranged in a split-split plot design, were setup with three levels of treatments with planting time/period as the main plot; pesticide application as the sub plot and variety as the sub-sub plot. The experiment was established in three replicates with plant spacing of $40 \mathrm{~cm} \times 20 \mathrm{~cm}$. The four planting periods followed the farmers' common planting calendar that starts in the last week of February onwards, through March and up to mid-April in the first rain season. The first rain season's experiment was planted in the last week of February, first week of March, third week of March and second week of
April in 2011A and 2012A. In the second rain season (2011B), the first, second, third and fourth sowings were done in the last week of August; $2^{\text {nd }}$ week of September, $2^{\text {nd }}$ week of October and $2^{\text {nd }}$ week of November, respectively. Half of the plots were sprayed using an insecticide (Dimethoiate) and a fungicide (Mancobez+/Metalaxyl), to manage insect pests and fungal diseases, respectively; while the other half was not sprayed (control).

The data collection included soil physical and chemical properties of experimental fields, weather (monthly rainfall, relative humidity and temperature) and plant agronomic characteristics (germination date, percentage germination, plant vigour, flowering date, podding days to maturity, percent plant survival and total grain yield), pest incidences and disease severity (DS). Soil physical and chemical properties were determined through laboratory analysis of composite soil samples collected from $0-15 \mathrm{~cm}$ depth at five points in each experimental field. The weather data were collected daily using a multi-weather transmitter. Disease severity data collection was initiated on the appearance of the first symptom, and weekly leaf area infections were scored using the $0-100 \%$ scale described by Reddy [18]. The percent disease severity scores were used to calculate Area Under Disease Progress Curve (AUDPC) using the following formula:

$$
\text { AUDPC } \left.\left.=\left[\left(X_{1}+X_{2}\right) * N_{1}\right) / 2\right]+\left[\left(X_{2}+X_{3}\right) * N_{2}\right) / 2\right] .1
$$

Where $X_{1}, X_{2}$ and $X_{3}$ represented DS on the $1^{\text {st }}, 2^{\text {nd }}$, $3^{\text {rd }} \ldots . . n^{\text {th }}$ assessment, whereas $\mathrm{N}_{1}$ and $\mathrm{N}_{2}$ were intervals (days) between every two data dates [19].

Analysis of Variance (ANOVA) was used to compare the efficacy and interaction across the different treatments based on means using GenStat $17^{\text {th }}$ Ed. (VNSI), and correlation analysis [20]. The Least Significant Difference test (LSD) at $\mathrm{P} \leq 0.05$ was used to assess pairwise significance of means when the overall ANOVA F-test was significant.

\section{Results}

The rains of 2011 and 2012 cropping seasons varied considerably from the typical rainfall patterns experienced in the zone. The first rain seasons in the two years delayed by one to two months, while the second season in 2011 had unusually high rainfall that appeared earlier and persisted throughout the entire season. In 2011A, the rains started at the end of March and stopped at the beginning of May (Table 1). In the second season of 2011B, rainfall started in June and continued through the entire season to December. In 2012A rain season, there were light rains in January and February, but rainfall gradually increased during the following months up to June (Table 1). Although higher rainfall was received during 2011B and 2012A rain seasons, its sparse distribution was not favourable for the highest agronomic performance of chickpea. This change in the rainfall pattern mostly affected the first and second crops in 2011 and 2012. There was deviation of the minimum temperatures (15-20, $15-25$ and $13-25^{\circ} \mathrm{C}$ ) and maximum temperatures (32-37, $31-37$ and $30-37{ }^{\circ} \mathrm{C}$ ) during 2011 A, 2011B and 2012A, respectively, from the normal $\left(18-29^{\circ} \mathrm{C}\right)$ for chickpea growth during the entire experimentation period. 
Table 1. On-station weather data recorded during 2011A, 2011B and 2012A in Mbarara, SWAEZ

\begin{tabular}{|c|c|c|c|c|c|c|c|c|}
\hline Season & Weather parameters & Mar & Apr & May & & & & \\
\hline \multirow[t]{5}{*}{$2011 \mathrm{~A}$} & Average Daily ${ }^{\circ} \mathrm{C}$ & 24.8 & 26.7 & 26.2 & & & & \\
\hline & Maximum & 34.8 & 36.8 & 32.6 & & & & \\
\hline & Minimum & 14.9 & 16.5 & 19.6 & & & & \\
\hline & Total Monthly Rainfall (cm) & 19.6 & 21.6 & 44.2 & & & & \\
\hline & & Jul & Aug & Sept & Oct & Nov & Dec & \\
\hline \multirow[t]{5}{*}{$2011 \mathrm{~B}$} & Average Daily ${ }^{\circ} \mathrm{C}$ & 24.1 & 22.1 & 22.5 & 30.0 & 30.8 & 22.5 & \\
\hline & Maximum & 31.4 & 29.9 & 34.4 & 37.0 & 36.6 & 34.0 & \\
\hline & Minimum & 16.8 & 14.5 & 17.1 & 22.9 & 25.0 & 19.8 & \\
\hline & Total Monthly Rainfall (cm) & 37.3 & 216.5 & 50.5 & 24.4 & 3.2 & 0.0 & \\
\hline & & Jan & Feb & Mar & Apr & May & Jun & Jul \\
\hline \multirow[t]{4}{*}{$2012 \mathrm{~A}$} & Average Daily ${ }^{\circ} \mathrm{C}$ & 30.0 & 30.8 & 27.3 & 21.9 & 21.9 & 21.9 & 21.6 \\
\hline & Maximum & 37.0 & 37.0 & 34.0 & 30.5 & 29.8 & 30.4 & 30.6 \\
\hline & Minimum & 22.9 & 25.0 & 19.6 & 13.3 & 14.0 & 13.4 & 12.6 \\
\hline & Total Monthly Rainfall (cm) & 3.2 & 0.0 & 32.5 & 141.6 & 67.7 & 15.0 & 4.0 \\
\hline
\end{tabular}

Mar-March, Apr-April, Jun-June, Jul-July, Aug-August, Sept-September, Oct-October, Nov-November, Dec-December.

Table 2. Physical-chemical characteristics of soils at the experimental sites on-station, MBAZARDI

\begin{tabular}{|c|c|c|c|c|c|c|c|c|c|c|c|}
\hline Season & pH & $\mathbf{O M}$ & $\mathbf{N}$ & $\mathbf{P}$ & $\mathbf{C a}$ & Mg & $\mathbf{K}$ & Sand & Clay & Silt & Textural class \\
\hline & & \multicolumn{2}{|c|}{ (-----\%-----) } & \multicolumn{4}{|c|}{ 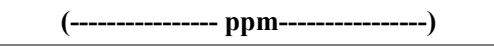 } & \multicolumn{4}{|c|}{ 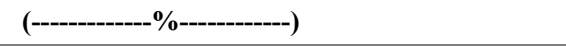 } \\
\hline $2011 \mathrm{~A}$ & 5.2 & 4.1 & 0.22 & 13.78 & 510.12 & 225.3 & 1142.9 & 61.1 & 28.9 & 10.0 & Sandy clay loam \\
\hline 2011B & 5.0 & 3.4 & 0.18 & 9.88 & 393.54 & 163.2 & 306.18 & 65.8 & 24.2 & 10.0 & Sandy clay loam \\
\hline $2012 \mathrm{~A}$ & 4.9 & 2.4 & 0.11 & 8.47 & 608.9 & 260.38 & 233.5 & 65.1 & 26.9 & 8.0 & Sandy clay loam \\
\hline Average & 5.0 & 3.3 & 0.2 & 10.7 & 504.2 & 216.3 & 560.9 & 64.0 & 26.7 & 9.3 & \\
\hline Critical levels & 5.2 & 3.0 & 0.20 & $<90$ & 350.0 & 100.0 & 150.0 & & & & \\
\hline Sufficient levels & $5.2-7.0$ & 6.0 & 0.30 & $90-230$ & 2000.0 & 600.0 & 500 & & & & \\
\hline
\end{tabular}

The soils at the experimental sites were characteristically sandy (61-66\%) implying that they had very low water and nutrient holding capacity. Total nitrogen and extractable phosphorus, which are responsible for vegetative, reproduction and pod development, were below the critical levels, whereas exchangeable potassium was sufficient in all the three sites (Table 2). The soil $\mathrm{pH}$ was low indicating low level of exchangeable bases.

\subsection{Growth Vigour of ICCV 00108 (Desi) and ICCV 92318 (Kabuli) Chickpea across Different Planting Periods}

The overall chickpea growth vigour trend across all planting times remained below the average, with a low rate of increase (Figure 1). Genotype ICCV 92318 displayed significantly higher plant growth vigour than ICCV 00108 during the three seasons. The second crop (planted on $5^{\text {th }}$ September) showed higher growth vigour, while the third ( $30^{\text {th }}$ October) showed intermediate and the fourth $\left(9^{\text {th }}\right.$ November) planting had the lowest growth vigour during 2011B (Figure 1). During 2012A, the first (before onset of rainfall) and second planting periods showed higher plant vigour than the third and fourth planting periods (at and after rainfall peak) (Figure 2). At the start of the dry season (June 2011B), as the maize check-crop started showing signs of moisture stress, chickpea growth vigour gradually reduced. The poor plant vegetative growth during $2011 \mathrm{~B}$ was attributed to the severe Ascochyta blight infection under continuous wet and cool weather conditions. However, the 2012A rainfall was adequate and chickpea had higher vigour.

\subsection{Effects of Planting Time, Pesticide Application and Variety on the Vegetative and Reproductive Performance of Chickpea}

Chickpea seeds planted before the on-set of rainfall (February and August), did not germinate until the rain seasons started (Table 3), and the insufficient soil moisture resulted in delayed germination of both chickpea genotypes. Also seed germination was poor for chickpea planted during second period (first week of March) of 2011A when the rainfall was scarce. The third and fourth (late March and mid-April) crops of 2012A coincided with sufficient rainfall, which resulted in early seed germination (within 4 to 7 days) while the first and second crops, which were planted during the dry spell delayed (12-13 days) to germinate (Table 3). Chickpea planted when soil moisture was sufficient geminated early regardless of the genotype. 


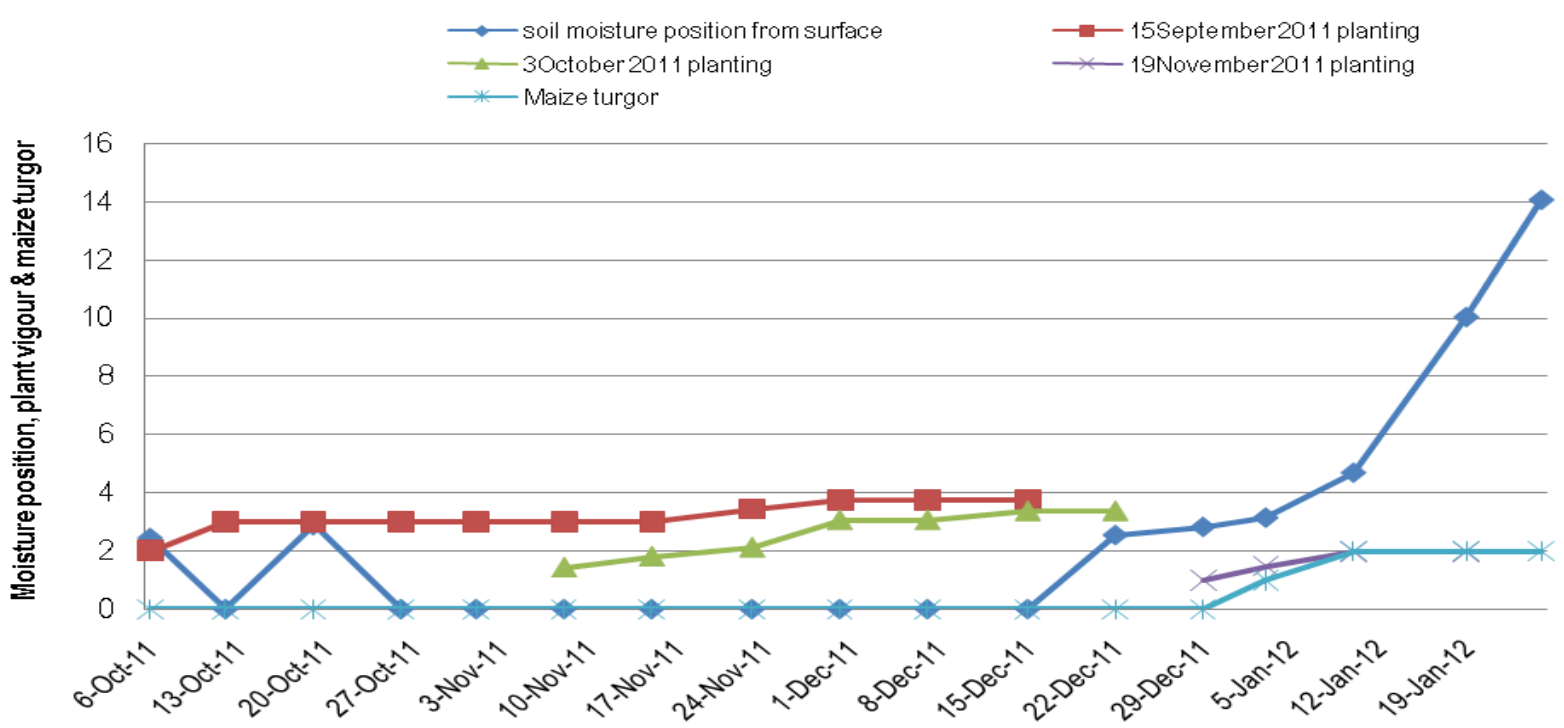

Figure 1. Response of chickpea plant vigour to soil moisture during 2011B. Soil moisture position from surface (cm), plant vigour, Maize turgor (14 Scale: 0 = none; 1 = Leave lost turgor; 2 = Leaves drooping; 3 = Leaves loosing green colour, 4 = plant wither/ drying)

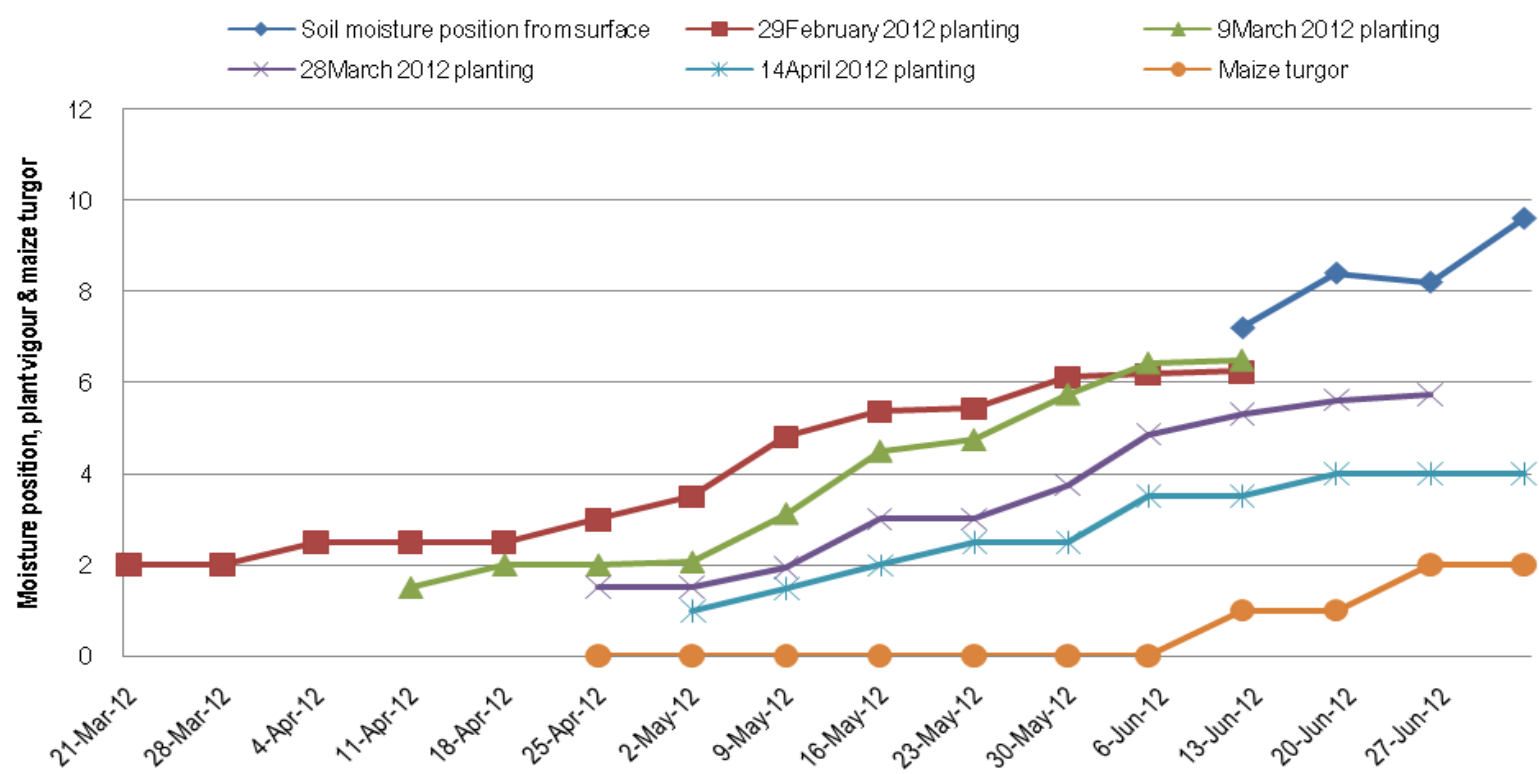

Figure 2. Effect of soil moisture on chickpea plant vigour during the growth period 2012A. Soil moisture position from surface (cm), plant vigour, Maize turgor (1-4 Scale: 0 = None; 1 = Leave lost turgor; 2 = Leaves drooping; $3=$ Leaves loosing green colour, $4=$ plant wither/ drying).

Table 3. Germination and growth vigour of two chickpea genotypes planted across different periods

\begin{tabular}{|c|c|c|c|c|c|c|c|c|c|}
\hline Genotype & Planting period & 2011B & $2012 \mathrm{~A}$ & $2011 \mathrm{~A}$ & 2011B & $2012 \mathrm{~A}$ & $2011 \mathrm{~A}$ & 2011B & $2012 \mathrm{~A}$ \\
\hline & & \multicolumn{2}{|c|}{ Day to germination } & \multicolumn{3}{|c|}{$\%$ Germination } & \multicolumn{3}{|c|}{ Plant vigour } \\
\hline \multirow[t]{4}{*}{ ICCV 00108} & First & $*$ & 13.0 & $*$ & * & 65.5 & $*$ & $*$ & 4.1 \\
\hline & Second & 7.0 & 13.0 & 31.2 & 73.9 & 60.3 & 4.5 & 3.0 & 4.0 \\
\hline & Third & 7.0 & 7.0 & 42.2 & 96.1 & 75.2 & 3.2 & 2.9 & 3.6 \\
\hline & Fourth & 8.0 & 6.0 & 92.5 & 71.1 & 69.1 & 2.5 & 2.0 & 2.9 \\
\hline \multirow[t]{4}{*}{ ICCV92318 } & First & $*$ & 13.0 & * & * & 60.2 & $*$ & * & 4.0 \\
\hline & Second & 7.0 & 12.0 & 45.2 & 52.3 & 50.2 & 4.9 & 3.0 & 3.8 \\
\hline & Third & 7.0 & 7.0 & 45.9 & 90.9 & 70.7 & 3.8 & 3.2 & 3.6 \\
\hline & Fourth & 7.0 & 6.0 & 86.7 & 72.5 & 71.8 & 2.6 & 2.0 & 2.9 \\
\hline $\operatorname{LSD}_{(\mathrm{P} \leq 0.05)}$ & & NS & 2.1 & 13.9 & 10.6 & 10.0 & 0.5 & 0.5 & 0.3 \\
\hline $\mathrm{CV} \%$ & & 0.0 & 8.6 & 22.3 & 9.0 & 10.1 & 12.7 & 15.7 & 6.3 \\
\hline
\end{tabular}

Season I: First-Last week of February; Second-2 $2^{\text {nd }}$ week of March; Third-last week of March; Fourth-2 $2^{\text {nd }}$ week of April. Season II: First-last week of August; Second- $2^{\text {nd }}$ week of September; Third- $2^{\text {nd }}$ week of October; Fourth- $2^{\text {nd }}$ week of November. *Not planted. 


\subsection{Effect of Planting Time and Fungicide Application on Ascochyta Blight Severity and Dry Root Rot Disease on Chickpea}

The high severities of Ascochyta blight and root rots that occurred on chickpea planted during the second period in 2011B, transformed into higher AUDPC (Table 6). In 2012A, the average severity and AUDPC of Ascochyta blight were higher on chickpea planted during the first period $(\mathrm{DS}=7.8 \%$, AUDPC $=169.5)$, followed by the second planting (DS $=3.8 \%$, AUPDC $=118.1$ ) and lowest on the third $(3.1 \%$, AUDPC $=28.4)$. There was no Ascochyta blight on chickpea was planted in the fourth period of $2012 \mathrm{~A}$. A similar trend was observed during
2011B. Chickpea planted after the rainfall peak, experienced the least Ascochyta blight infection. Genotype ICCV 00108 had higher Ascochyta blight infection (AUDPC = 89.7) than ICCV 92318 (AUDPC = 68.4). The planting date $\mathrm{x}$ variety interaction of AUDPC was significantly different $(\mathrm{P} \leq 0.05)$. There was negative correlation between the Ascochyta blight AUDPC and grain yields of chickpea $(\mathrm{r}=-0.158, \mathrm{r}=-0.171)$ in $2011 \mathrm{~B}$ and $2012 \mathrm{~A}$.

Incidences of dry root rot disease (caused by Rhizoctonia bataticola) were significant $(\mathrm{P} \leq 0.05)$ different across the three seasons. The disease incidences were inconsistent across variety and planting period (Table 7). However, given the low level of infections, the disease was not a major threat to chickpea production in the zone.

Table 6. Ascochyta blight disease severity and Area under Disease Progress Curve (AUDPC) on chickpea

\begin{tabular}{|c|c|c|c|c|c|c|c|}
\hline \multirow[t]{2}{*}{ Genotypes } & \multirow[t]{2}{*}{ Planting period } & \multicolumn{2}{|c|}{$2011 \mathrm{~A}$} & \multicolumn{2}{|c|}{$2011 \mathrm{~B}$} & \multicolumn{2}{|c|}{$2012 \mathrm{~A}$} \\
\hline & & $\%$ Severity & AUDPC & $\%$ Severity & AUDPC & \% Severity & AUDPC \\
\hline \multirow[t]{4}{*}{ ICCV 00108} & First & $*$ & $*$ & $*$ & $*$ & 4.8 & 212.2 \\
\hline & Second & 1.0 & 39.4 & 8.1 & 160.0 & 2.4 & 118.1 \\
\hline & Third & 1.8 & 76.6 & 2.5 & 18.0 & 0.7 & 28.4 \\
\hline & Fourth & 1.3 & 56.9 & 2.5 & 18.0 & 0.0 & 0.0 \\
\hline \multirow[t]{4}{*}{ ICCV92318 } & First & $*$ & $*$ & $*$ & $*$ & 2.7 & 126.9 \\
\hline & Second & 2.3 & 98.4 & 10.6 & 223.0 & 2.4 & 118.1 \\
\hline & Third & 2.5 & 105.0 & 2.5 & 17.0 & 0.7 & 28.4 \\
\hline & Fourth & 1.0 & 41.6 & 2.5 & 17.0 & 0.0 & 0.0 \\
\hline $\operatorname{LSD}_{(\mathrm{P} \leq 0.05)}$ & & 0.7 & 50.7 & 4.2 & 80.1 & 0.9 & 45.5 \\
\hline $\mathrm{CV} \%$ & & 46.5 & 47.2 & 81.0 & 97.4 & 37.1 & 38.4 \\
\hline
\end{tabular}

Season I: First-Last week of February; Second-2 ${ }^{\text {nd }}$ week of March, Third-last week of March, Fourth-2 ${ }^{\text {nd }}$ week of April. Season II: First-last week of August; Second- $2^{\text {nd }}$ week of September; Third- $2^{\text {nd }}$ week of October; Fourth- $2^{\text {nd }}$ week of November. ${ }^{*}$ Not planted.

Table 7. Dry root rot disease and pod borer incidences on chickpea planted on different dates with/without pesticide application

\begin{tabular}{|c|c|c|c|c|c|}
\hline Planting period & $2011 \mathrm{~A}$ & 2011B & $2012 \mathrm{~A}$ & $2011 \mathrm{~A}$ & 2011B \\
\hline & \multicolumn{3}{|c|}{$\%$ Dry Root Rot Incidence } & \multicolumn{2}{|c|}{$\%$ Pod Borer Incidence } \\
\hline First & * & $*$ & 1.5 & * & $*$ \\
\hline Third & 2.4 & 0.8 & 0.2 & 38.7 & 0.0 \\
\hline Fourth & 2.7 & 0.0 & 0.1 & 33.2 & 0.0 \\
\hline $\operatorname{LSD}_{(\mathrm{P} \leq 0.05)}$ & 1.9 & 1.9 & 0.5 & NS & 8.6 \\
\hline $\mathrm{CV} \%$ & 95.8 & 164.0 & 83.2 & 64.8 & 76.9 \\
\hline
\end{tabular}

Season I: First-Last week of February; Second- $2^{\text {nd }}$ week of March; Third-last week of March; Fourth-2 ${ }^{\text {nd }}$ week of April. Season II: First-last week of August; Second- $2^{\text {nd }}$ week of September; Third- $2^{\text {nd }}$ week of October; Fourth- $2^{\text {nd }}$ week of November. * Not planted.

Table 8. Interactive effects of variety, planting period and pesticide application on yield (Kg/ha) performance of chickpea in SWAEZ

\begin{tabular}{|c|c|c|c|c|c|c|c|}
\hline \multirow[t]{2}{*}{ Variety } & \multirow[t]{2}{*}{ Planting period } & \multicolumn{2}{|c|}{$2011 \mathrm{~A}$} & \multicolumn{2}{|c|}{$2011 B$} & \multicolumn{2}{|c|}{$2012 \mathrm{~A}$} \\
\hline & & Sprayed & Non sprayed & Sprayed & Non sprayed & Sprayed & Non sprayed \\
\hline \multirow[t]{3}{*}{ ICCV 00108} & First & $*$ & $*$ & $*$ & $*$ & 1079.5 & 965.9 \\
\hline & Third & 416.7 & 370.4 & 557.2 & 812.3 & 1238.6 & 1136.4 \\
\hline & Fourth & 231.5 & 162.0 & 236.1 & 225.5 & 818.2 & 1215.9 \\
\hline \multirow[t]{4}{*}{ ICCV92318 } & First & $*$ & $*$ & * & $*$ & 1011.4 & 636.4 \\
\hline & Second & 879.6 & 601.9 & 257.9 & 415.3 & 863.6 & 681.8 \\
\hline & Third & 601.9 & 555.6 & 537.5 & 554.2 & 1090.9 & 1170.5 \\
\hline & Fourth & 300.9 & 115.7 & 300.5 & 207.9 & 1045.5 & 795.5 \\
\hline AVERAGE & & 520.8 & 347.2 & 359.1 & 461.0 & 1024.1 & 911.9 \\
\hline $\operatorname{LSD}_{(\mathrm{P} \leq 0.05)}$ & & \multicolumn{2}{|c|}{190.4} & \multicolumn{2}{|c|}{139.1} & \multicolumn{2}{|c|}{562.2} \\
\hline $\mathrm{CV} \%$ & & \multicolumn{2}{|c|}{28.5} & \multicolumn{2}{|c|}{22.0} & \multicolumn{2}{|c|}{38.7} \\
\hline
\end{tabular}

Season I: First-Last week of February; Second-2 ${ }^{\text {nd }}$ week of March; Third-last week of March; Fourth-2 ${ }^{\text {nd }}$ week of April. Season II: First-last week of August; Second- $2^{\text {nd }}$ week of September; Third- $2^{\text {nd }}$ week of October; Fourth- ${ }^{\text {nd }}$ week of November. ${ }^{*}$ Not planted. 


\subsection{Effects of Planting Time and Pesticide Application on Pod Borer Incidences on Chickpea}

Chickpea that had not been sprayed with insecticides had higher pod borer infestation $(74.4 \%)$. However, there were no significant $(\mathrm{P} \leq 0.05)$ differences in pest incidences on chickpea across the four planting periods in 2011A season. Very low pod borer infestation occurred on the chickpea planted during the first week of September (second planting) in 2011B (Table 7). This season was generally rainy and cold, thus unfavourable for pod borer infestation of chickpea.

\subsection{Effects of Planting Time and Pesticide Application on Chickpea Grain Yield}

Integration of planting time and pesticide application had significant $(\mathrm{P} \leq 0.05)$ influence on chickpea grain yields. Higher grain yields were observed when chickpea was planted in October, 2011B. Low grain yields were observed when chickpea was planted in November, 2011B. With moderate and even rainfall distribution, higher grain yields were harvested in 2012A. Crops that were planted at or just after 'rainfall peak' (end of March) had higher grain yields when sprayed against pests and disease (Table 8). Although the ICCV 92318 is well adapted to cool temperate conditions, its grain yields in the wet and cool season 2011B season was generally lower compared to ICCV 00108 that is known to be well adapted to tropical conditions. Therefore, this study revealed that integrating a high yielding (ICCV 00108) variety with timely planting just after the peak rainfall (third planting period) and pesticide application (1-2 sprays) led to high yield performance of chickpea in the SWAEZ.

\section{Discussion}

Although chickpea is well known to be a cool weather adapted crop, varieties well adapted to low rainfall conditions $[21,22,23]$, have been developed. Genotypes ICCV 00108 and ICCV 92318 performed well under the low rainfall and highly sandy soil conditions in the SWAEZ. The optimum temperatures range for a good chickpea crop is $18-29^{\circ} \mathrm{C}$, but in the SWAEZ such favourable conditions typically occur just after the peak rainfall period in late March or early April during the first season, and during the whole of October in the second season. Moreover, chickpea performed better when planted just after the rainfall peak followed by gradual reduction in moisture up to the end of the pod development stage agreeing with Upadhyaya et al. (2012), who reported higher chickpea grain yields in India and Kenya from the crops planted post the rain seasons [24]. Nevertheless, chickpea is highly sensitive to severe drought and very high temperature especially during the vegetative and reproductive stages because these conditions create irrecoverable damages resulting from excessive moisture stress [25,26,27].

Chickpea planted towards the end of the rain season usually coincide with high temperatures associated with the dry conditions that lead to high pest infestation especially the Helicoverpa armigera, which is a very important insect pest in major chickpea growing areas $[17,28,29]$. The average pod borer infestation range of $33-40 \%$ measured across the three planting periods of 2011A were consistent with findings previously reported in Uganda [30], India and Kenya where Kabuli was similarly found to be highly susceptible to the pod borer than Desi $[21,29]$. Although a strong positive correlation between pod borer infestation and drought has been reported elsewhere [17], the level of infestation varies across chickpea variety as previously reported by Sarwar [28]. Pest damages have been found proportional to the pest population [31]. Because wet and cool seasons were unfavourable for the pod borer larvae development and survival in this study, crops that coincided with these conditions displayed negligible or low infestation. To avoid pod borer infestation, chickpea is best planted just after beginning of rainfall season with conditions that are not favourable for the larvae survival. However, because rainy periods are highly favourable to Ascochyta blight, growing of the Desi types during the wet and cool seasons was an appropriate chickpea production strategy against pod borer infestation.

High humidity and cool conditions favour disease development especially fungal diseases such as Ascochyta blight that has been found common in major chickpea growing regions [15]. Chickpea sown during the first and second periods received higher rainfall than the third and fourth crops in each season. The high Ascochyta blight severity experienced by the first and second crops during 2011B and 2012A resulted into low chickpea grain yields. Severity of Ascochyta blight reduced with decrease in rainfall as this affected humidity that favours proliferation of the fungal pathogen. Kabuli type (ICCV 92318) showed more resistance to Ascochyta blight resistance than Desi (ICCV 00108) genotype. There were negative correlations between the Ascochyta blight AUDPC and grain yield implying that increase in disease resulted in yield reduction. Kabuli genotypes have been found to carry higher levels of resistance to Ascochyta blight $[18,32]$. Reddy and Singh (1984) discovered that sufficient resistance to Ascochyta blight exists in the vegetative growth stages of most Kabuli and Desi genotypes, but both lack resistance at podding stage, thus creating a need to secure resistance found in some rare genotypes with resistance at vegetative and reproductive stages. The study indicated that integrating high resistance and timely planting in controlling Ascochyta blight was effective. However, judicial fungicide application in the technology combinations especially for genotypes with moderate resistance may be appropriate and economically viable [3,32,33].

Planting time, pesticide application and genotype had significant influence on agronomic performance of chickpea. Planting chickpea before or at the onset of the rains delayed germination (13 days), yet when planted after peak rains took approximately one week to germinate in the SWAEZ. The low percentage germination was partly attributed to pest attack of seed, while the low plant population resulted into higher plant vigour due low competition for soil moisture and nutrients. On the other hand, chickpea planted after the peak of the rains had higher percentage germination and plant density but with lower plant vigour, which deviates from the findings of 
the effect of planting time on winter Kabuli in the Mediterranean region [34,35]. Chickpea takes longer period to mature when planted early in the season due to prolonged vegetative growth resulting from excess soil moisture and high humidity that are also conducive for high fungal disease epidemics such as Ascochyta blight. Chickpea planted immediately after peaks of the rains had the highest grain yields. This indicated that planting chickpea just after peak of the rain season is critical if farmers are to include this crop in the existing banana farming system common in the SWAEZ.

\section{Conclusion}

This study revealed that the semi-arid SWAEZ of Uganda is suitable for chickpea production with a yield potential of over $1500 \mathrm{~kg} \mathrm{ha}^{-1}$ that is close to the average yield of $1900 \mathrm{Kg} / \mathrm{ha}$ attained in the major producing countries. Higher chickpea yield can be attained from the crop planted after the peak of the rain season, which normally occurs toward the end of March and midOctober, when the weather conditions are unfavourable for severe pests and diseases such as pod borer and Ascochyta blight. Integration of plant disease resistance and appropriate planting time led to management of major chickpea pests and diseases that in turn led to increased grain yields. However, to enhance chickpea grain yields, the soil nutrient and physical conditions of the sandy soils of the SWAEZ need to be modified with appropriate soil fertility improving innovations.

\section{Funding}

This work was funded by McKnight Foundation through a collaborative project of enhancing sustainable productivity and utilization of chickpea (Cicer arietinum), pigeon pea (Cajanus cajan) and cowpea (Vigna unguiculata) in the banana farming system of Uganda.

\section{Acknowledgements}

The authors greatly appreciate the McKnight Foundation in USA, for funding the chickpea research project within which this study was carried out in Uganda. The contribution of the National Agricultural Research Organization (NARO), Foundation for AIDS Orphaned Children (FAOC) and School of Food Technology, Nutrition and Bio-engineering of Makerere University in implementing the project are greatly appreciated. Special thanks go to Dr. Salim Ali formally working for the International Crops Research Institute for the Semi-Arid Tropics (ICRISAT), Nairobi, Kenya for kindly providing the chickpea germplasm for research. Thanks to Mutenyo H., Kyomugisha M., Ampurira B., and Natuha S., for the technical support in establishment and management of on-station field experiments.

\section{Conflicts of Interest}

The authors have no competing interests.

\section{References}

[1] Gholipoor, M., Potential effects of individual versus simultaneous climate change factors on growth and water use in chickpea. International Journal of Plant Production, 2012. 1(2): p. 189-204.

[2] Kumar, P., D. Shah, and M.P. Singh, Evaluation of chickpea (Cicer arietinum L.) genotypes for heat tolerance: a physiological assessment. Indian Journal of Plant Physiology, 2017. 22(2): p. 164-177.

[3] Pande, S., et al., Ascochyta blight of chickpea (Cicer arietinum L.) a review of biology, pathogenicity, and disease management. Australian Journal of Agricultural Research, 2005. 56(4): p. 317332.

[4] Yadav, R., et al., Drought and Heat Tolerance in Chickpea: Transcriptome and Morphophysiological Changes Under Individual and Combined Stress, in Plant Tolerance to Individual and Concurrent Stresses. 2017, Springer. p. 91-109.

[5] Gaur, P., et al. Chickpea Seed Production Manual. Patancheru 502 324, Andhra Pradesh, India: International Crops Research Institute for the Semi-Arid Tropics. 28 pp. 2010. ICRISAT.

[6] Barrios, E., et al., Indicators of soil quality: A South-South development of a methodological guide for linking local and technical knowledge. Geoderma, 2006. 135: p. 248-259.

[7] Minasny, B. and A. McBratney, Limited effect of organic matter on soil available water capacity. European Journal of Soil Science, 2018. 69(1): p. 39-47.

[8] Pande, S., et al., Identification of sources of multiple disease resistance in mini-core collection of chickpea. Plant Disease, 2006 90(9): p. 1214-1218.

[9] Gan, Y., et al., Management options for minimizing the damage by ascochyta blight (Ascochyta rabiei) in chickpea (Cicer arietinum L.). Field Crops Research, 2006. 97(2-3): p. 121-134

[10] Cherry, A., et al., Field evaluation of Helicoverpa armigera nucleopolyhedrovirus formulations for control of the chickpea pod-borer, H. armigera (Hubn.), on chickpea (Cicer arietinum var. Shoba) in southern India. Crop Protection, 2000. 19(1): p. 51-60.

[11] Patil, S.B., et al., Sustainable management of chickpea pod borer. A review. Agronomy for Sustainable Development, 2017. 37(3): p. 20.

[12] Gan, Y., et al., Management options for minimizing the damage by Ascochyta blight (Ascochyta rabiei) in chickpea (Cicer arietinum L.). Field Crops Research, 2006. 97(2): p. 121-134.

[13] Baite, M.S. and S.C. Dubey, Pathogenic variability of Ascochyta rabiei causing blight of chickpea in India. Physiological and Molecular Plant Pathology, 2018.

[14] Reddy, M. and K. Singh, Relationship between ascochyta blight severity and yield loss in chickpea and identification of resistant lines. Phytopathologia Mediterranea, 1990: p. 32-38.

[15] Tadesse, M., L. Turoop, and C.O. Ojiewo, Survey of Chickpea (Cicer arietinum L) Ascochyta Blight (Ascochyta rabiei Pass.) Disease Status in Production Regions of Ethiopia. Plant, 2017. 5(1): p. 22-30

[16] Attar, B., Genetics of virulence and pathogenic diversity for Ascochyta Blight affecting chickpea. 2017, M.Sc. Thesis. Institute of Natural and Applied Sciences of Çukurova University. Turkey. $84 \mathrm{pp}$.

[17] Rehman, S.U., et al., Screening of some chickpea (Cicer arietinum L.) varieties against Helicoverpa armigera under semi arid climatic conditions. Legume Research-An International Journal, 2017. 40(2): p. 379-383

[18] Reddy, M. and K. Singh, Evaluation of a world collection of chickpea germplasm accessions for resistance to Ascochyta blight. Plant Disease, 1984. 68(10): p. 900-901.

[19] Jeger, M. and S. Viljanen-Rollinson, The use of the area under the disease-progress curve (AUDPC) to assess quantitative disease resistance in crop cultivars. TAG Theoretical and Applied Genetics, 2001. 102(1): p. 32-40.

[20] Steel, R.G., J.H. Torrie, and D.A. Dickey, Principles and Procedures of statistics. A Biometric Approach, in 1997, McGraw Hill Book Company Inc., New York. p. 204-227.

[21] Mulwa, R., P. Kimurto, and B. Towett. Evaluation and selection of drought and pod borer (Helicoverpa armigera) tolerant chickpea genotypes for introduction in semi-arid areas of Kenya. in Second RUFORUM biennial meeting. 2010. 
[22] Thudi, K., et al., An Overview Of Chickpea Research: From Discovery To Delivery. Pulse India, 2017. 2(5): p. 22-25.

[23] Urrea, C.A., F.J. Muehlbauer, and R.M. Harveson, Registration of 'New Hope'Chickpea Cultivar with Enhanced Resistance to Ascochyta Blight. Journal of Plant Registrations, 2017. 11(2): p. 107-111.

[24] Upadhyaya, H.D., et al., Phenotyping chickpeas and pigeonpeas for adaptation to drought. Frontiers in physiology, 2012. 3.

[25] Mallu, T.S., Evaluation of Chickpea Genotypes for Yield and Selected Agronomic Traits in Kenya. 2015.

[26] Devasirvatham, V., et al., Effect of high temperature on the reproductive development of chickpea genotypes under controlled environments. Functional Plant Biology, 2012. 39(12): p. 10091018.

[27] Sivasakthi, K., et al., Chickpea, in Water-Conservation Traits to Increase Crop Yields in Water-deficit Environments. 2017, Springer. p. 35-45.

[28] Sarwar, M., N. Ahmad, and M. Tofique, Identification of susceptible and tolerant gram (Cicer arietinum L.) genotypes against gram pod borer (Helicoverpa armigera Hubner). Pak J Bot, 2011. 43: p. 1265-270
[29] Yadav, S.S., et al., Evaluation of Helicoverpa and drought resistance in desi and kabuli chickpea. Plant Genetic Resources, 2006. 4(3): p. 198-203.

[30] Ogenga- Latigo, M., J. Obuo, and P. Orotin, Infestation and pod damage by Helicoverpa armigera (Hubner) on Chickpea (Cicer arietinum L.) in Uganda. International journal of pest management, 1994. 40(3): p. 245-248.

[31] Hossain, M.A., A.A. Haque, and M. Prodhan, Incidence and damage severity of pod borer, Helicoverpa armigera (Hubner) in chickpea (Cicer arietinum L.). Bangladesh Journal of Scientific and Industrial Research, 2009. 44(2): p. 221-224.

[32] Ahmed, H., et al., Components of disease resistance in Desi and Kabuli chickpea varieties against Ascochyta blight. Plant Pathology Journal, 2006. 5(3): p. 336-342.

[33] Jackson-Ziems, T.A., et al., Understanding Fungicide Resistance. Papers in Plant Pathology, 2017: p. 481.

[34] López-Bellido, F.J., et al., Effect of planting date on winter kabuli chickpea growth and yield under rainfed Mediterranean conditions Agronomy journal, 2008. 100(4): p. 957-964.

[35] Ruggeri, R., et al., Effects of seeding date and seeding rate on yield, proximate composition and total tannins content of two kabuli chickpea cultivars. Italian Journal of Agronomy, 2017. 11 